\title{
Path Analysis on the Antecedents of IT Application Innovation Level: An Empirical Investigation
}

\author{
Wenwen $\operatorname{Pan}^{1,2}$ and Guangwei $\mathrm{Hu}^{2}$ \\ ${ }^{1}$ College of Economics and Management, Nanjing University of Posts and \\ Telecommunications \\ ${ }^{* 2}$ School of Information Management, Nanjing University \\ jsnjpwwen@126.com,hugw@nju.edu.cn
}

\begin{abstract}
The study empirically tested a research model for identifying the linkages among IT management mechanism, IT application level and IT application innovation level, based on a sample of 530 manufacturing enterprises in Jiangsu Province, China. Results indicated that IT management mechanism had significant and positive influences on IT application level and IT application innovation level. Meanwhile, IT application level had a fully mediating effect between IT management mechanism and IT application innovation level. This research might be some new implications for the managers of manufacturing industry to improve their organizations' IT innovation level.
\end{abstract}

Keywords: Manufacturing Industry; Management Mechanism; IT Application; IT Application Innovation; Confirmatory Factor Analysis

\section{Introduction}

At the stage of China's economic transition, central government proposed the twelfth fiveyear plan to continuously enhance the speed of China's industry development. The merging of informatization and industrialization is selected as one of the channels in the plan $[1,2]$. To conduct it, the levels of Information technology (IT) application and innovation are very important to the promotion of independent innovation and competitive ability of China's manufacturing firms. Practices in many developed countries shows that IT applications and innovations are efficient ways to the goals of "intelligent manufacturing" and "green manufacturing" [3-5]. Therefore, IT is usually considered as an enabler to improve the innovation capability and accelerate the transformation in many fields, such as research and development (R\&D), manufacturing, marketing and management, and finally, can help to turn the role of China from a "big manufacturing country" to a "powerful manufacturing country", and from "made in China" to "intellectually made in China".

However, there are few studies argue the issues on the relationships among IT management mechanism (ITMM), IT application level (ITAL) and IT application innovation level (ITAIL). This article employed structure equation modeling approach to explore possible, latent relationships and evolution paths among them. The results provide reference models for stakeholders to improve the performance of manufacturing industry of China.

\section{Literature Review}

Reviewing the literatures of the last ten years, there are various research perspectives in manufacturing informatization fields. Generally, the studies can be divided into two 
mainstreams. The one is from technical perspective, which focused on the development and application of advanced IT (e.g., Internet, virtual simulation, grid computing, cloud computing and internet of things) in products $\mathrm{R} \& \mathrm{D}$, production and improvement [3-8]. The other is from management perspective, which focused on the impact of management factors (e.g., IT innovation and diffusion) on the IT application and IT application innovation level, such as decision-making mode, management intentions, chief information officer (CIO) role, user acceptance and capital investment [4, 9-11]. Recently, studies have a trend to transfer a single view of the emphasis on technology or management factors to a multi-angle and multifactor view that integrates technology and management factors [4, 5, 12-16]. Additionally, there are further studies on what kind of effects that IT has on the organizational performance [2-4]. And most researchers accept the opinion that only technical adaptation is not enough for the success of IT application and innovation, and it should also rely on a good management mechanism to enhance the adaptation of IT with organization [17-20]. Theories of IT absorption, assimilation, and diffusion are all discussing about this theme. Some studies have already confirmed that IT management mechanism (ITMM), IT application level (ITAL), and IT application innovation level (ITAIL) all have significant impacts on manufacturing enterprises' performance [4, 14]. However, the linkages and influence mechanism among ITMM, ITAL and ITAIL are still lack of empirical studies.

To solve this problem, a research model was proposed in this paper and the related investigation was conducted using the data collected from manufacturing industry of Jiangsu province, China. The study aims to find some effective ways to promote IT innovation level of China's manufacturing industry.

\section{Research Model and Hypotheses}

\subsection{IT Management Mechanism}

Empirical studies showed that the management factors were closely related to the promotion of IT application level and IT application innovation level [6, 11, 21]. Some most concerned factors are as follows: organization management mode, leadership, capital investment, and matching degree between tissue culture and IT application level, etc. [11, 22]. For example, Wong et al., [6], Stacie et al., [9], and He [23] found that organization management mode (especially decision-making mode) had a significant impact on the performance of IT Implementation and IT innovation. Other studies also suggested that top manager's support had a major impact on the development of information systems (IS), and IT innovation [10, 11]. Wu and Ong [12] confirmed capital investment was an important factor to the success of IT application and innovation. In their study, an adequate funding was regarded as a necessary material basis for the success of IT application and innovation. While, the level of capital investment was mainly decided by multi-factors such as top manager's support, enterprise scale, and so on [18, 19]. The above-mentioned studies clearly demonstrate that a good IT management mechanism leads to higher level of IT application and IT application innovation in manufacturing enterprises.

So, we proposed the following hypotheses:

H1: IT Management mechanism (ITMM) of manufacturing enterprise has positive and direct effect on its IT application level (ITAL);

H2: IT Management mechanism (ITMM) of manufacturing enterprise has positive and direct effects on its IT application innovation level (ITAIL). 


\subsection{IT Application Level}

According to the innovation diffusion theory, IT can provide necessary knowledge and information channels for the organizational innovation diffusion [11]. And the application and absorption of new IT is often the enabler of IT innovation [20, 24]. Zeng et al., [25] found IT application may contribute to knowledge sharing in enterprise, thus, may create a precursor condition for IT application innovation. Furthermore, Wang and Ramiller confirmed from the perspective of organizational learning, that IT application could accelerate the IT knowledge sharing process. Thus, IT application can effectively eliminate knowledge barriers to the acceptance and absorption of IT innovation in organization, and promote the IT application innovation performance [26].

According to our analysis, during the process of introduction and application of IT, enterprises may discover lots of problems in their original business processes, or technical programs, and may gradually try to make some improvements. These efforts will stimulate the continuous generation of IT application innovation. So the maturity of IT application may be an antecedent and foundation of IT application innovation. Thus, higher IT application level usually leads to higher IT application innovation level.

Based on this discussion, it was reasonable to provide the following hypothesis:

H3: IT application level (ITAL) of manufacturing enterprise has positive and direct effects on its IT application innovation level (ITAIL).

\subsection{The Structure Model}

Based on the above-mentioned hypotheses, we built a structural model which constructed the linkages among IT management mechanism, IT application level, and IT application innovation level (shown in Figure 1). In this model, the latent variables were IT management mechanism, IT application level, IT application innovation level, management informatization (MI), production informatization (PI), research informatization (RI) and business informatization (BI). As to IT application level, it included four second-order latent variables (i.e., MI, PI, RI and $\mathrm{BI}$ ).

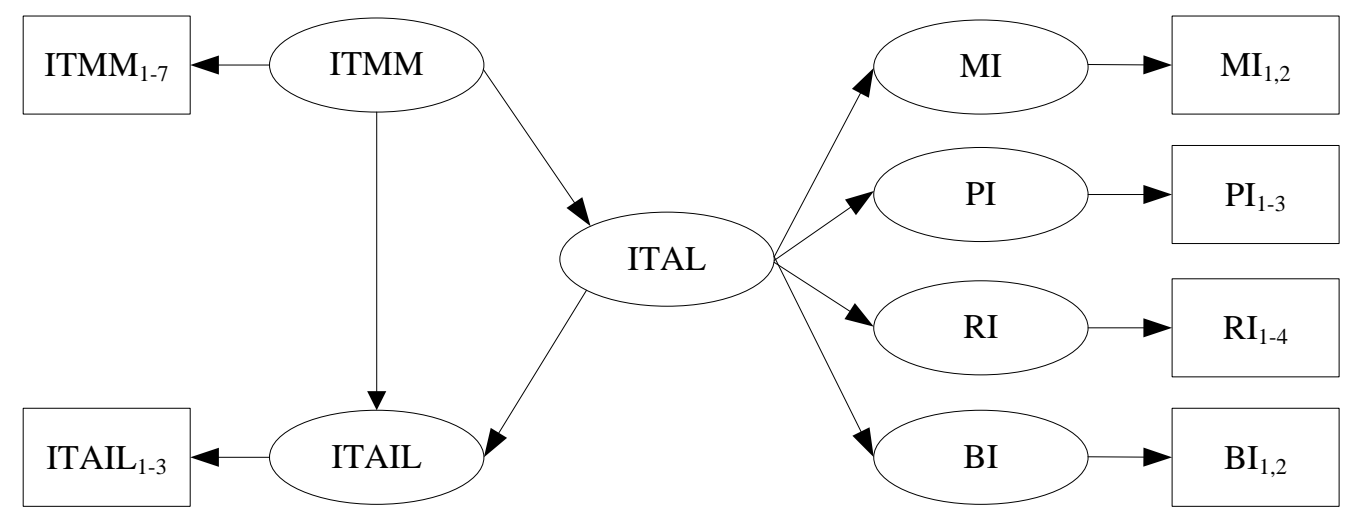

Figure 1. The structure model

Furthermore, we proposed that:

H4: IT application level (ITAL) of manufacturing enterprise plays a mediating role between its management mechanism (ITMM) and IT application innovation level (ITAIL). 
H4a: ITAL of manufacturing enterprise plays a totally mediating role between ITMM and ITAIL.

H4b: ITAL of manufacturing enterprise plays a partially mediating role between ITMM and ITAIL.

\section{Research Method}

\subsection{Scale Development}

We reviewed the works of highly cited authors such as Thakur and Jain [3], Wong et al., [6], Evangelista and Vezzani [15], and Zeng et al., [25] to extract the practical and operable items used in the evaluation of IT Management mechanism, IT application level and IT application innovation level. A group containing the possible items was developed for the evaluation of IT Management mechanism, IT application level and IT application innovation level.

An online Delphi method was employed to ensure the reliability and validity of measurement scale. The experts were selected from three areas: universities (e.g., Nanjing University and Southeast University), Information resource management institutions (e.g., Jiangsu Information Center and Jiangsu Development \& Reform Commission), and enterprises (e.g., NARI company).

Based on the literatures $[10,11]$ and the experts' suggestions, a set of seven observation items was adopted to measure IT management mechanism (ITMM). These items included group decision-making model (ITMM1), professional advisory (ITMM2), informatization organizing (ITMM3), annual budget (ITMM4), growth rate of investment (ITMM5), leader's support (ITMM6), and policy (ITMM7).

For IT application level (ITAL), it was measured by four key functional IT applications in manufacturing enterprises, which were management informatization (MI) [4], production informatization (PI) [9, 10], research informatization (RI) $[10,13]$, and business informatization (BI) [10, 14]. MI was measured by OA (MI1) and ERP (MI2); PI was measured by Computer Aided Manufacturing (PI1), Manufacturing Execution System (PI2) and Numerical Control System (PI3); RI was measured by Computer Aided Design (RI1), Computer Aided Engineering (RI2), Computer Aided Process Planning (RI3) and Virtual Product Development (RI4); And BI was measured by Enterprise Homepage (BI1) and Ecommerce (BI2).

Considering some new presence technologies, such as the internet of things, cloud computing, they are being used in manufacturing enterprises. In order to be consistent with the current IT innovation situation, we adopted the conception of IT application innovation level (ITAIL), which was measure by several key supportive and familiar technologies, including RFID (ITAIL1), mobile applications (ITAIL2) and SOA (ITAIL3). The observation items mentioned above were measured using a 5-point Likert scale.

\subsection{Data Collection}

As a manufacturing industry gathering place in Yangtze River Delta economic area, there are many different kinds of manufacturing enterprises in Jiangsu province [27], which were chosen as a presentation to carry out our research. The samples were selected by the stratified random sampling, and investigation range was classified according to the area division of 13 cities of Jiangsu province. Data collection using self-administered questionnaires were distributed to 530 top managers and technical staffs in different kinds of manufacturing enterprises, such as mechanics, electronics, metallurgy, Pharmaceuticals, textile industry. Of 
the 530 questionnaires, a total of 246 questionnaires were returned. Thirty questionnaires were eliminated due to their large missing values. The overall response rate was $40.8 \%$ (216/530), which was considered suitable for further analysis (see Table 1).

Table 1. Demographics and descriptive statistics $(n=216)$

\begin{tabular}{l|l|l|l|l|l}
\hline \multicolumn{1}{c|}{ Categories } & $\boldsymbol{N}$ & Percentage & Categories & $\boldsymbol{N}$ & Percentage \\
\hline Business type & & & Region & & \\
Electronics & 31 & 14.352 & Nanjing & 27 & 12.500 \\
Mechanics & 80 & 37.037 & Zhenjiang & 12 & 5.556 \\
Transportation & 26 & 12.037 & Changzhou & 48 & 22.222 \\
Petrochemicals & 6 & 2.778 & Wuxi & 25 & 11.574 \\
Food \& beverage & 27 & 12.500 & Suzhou & 25 & 11.574 \\
Metallurgy & 4 & 1.852 & Nantong & 17 & 7.870 \\
Pharmaceuticals & 4 & 1.852 & Yangzhou & 9 & 4.167 \\
Others & 38 & 17.593 & Taizhou & 17 & 7.870 \\
Manager & 189 & 87.500 & Xuzhou & 7 & 3.241 \\
Top-level & 51 & 23.611 & Suqian & 3 & 1.389 \\
Middle-level & 131 & 60.648 & Huaian & 6 & 2.778 \\
Basic-level & 7 & 3.241 & Lianyungang & 7 & 3.241 \\
Technologist & 27 & 12.500 & Yancheng & 13 & 6.019 \\
Top-level & 15 & 6.944 & Total employees & & \\
Middle-level & 11 & 5.093 & >=2000 & 53 & 24.537 \\
Basic-level & 1 & 0.463 & $300-2000$ & 74 & 34.259 \\
\hline
\end{tabular}

\section{Data Analysis}

\subsection{Measurement Model Testing}

Given that the instruments were summarized from the existing studies, we first tested the construct through two independent stages. We tested the reliability of questionnaires using SPSS17.0. The results showed that Cronbach's Alpha Coefficients (standard value) of each item were all above 0.80 , and the value of ITAL exceeded 0.94 . Thus, the internal consistency of each item was good, and the data were suitable for factor analysis.

The overall construct validity was tested using CFA. The scale validation of the constructs was checked first. To examine the goodness of fit to the overall CFA model, a correlation was imposed so that the $\chi^{2}$ normalized by degree of freedom $\left(\chi^{2} / d f\right)$ should not exceed 3 . In addition, the goodness of fit index (GFI) and normed fit index (NFI) exceeded 0.90, and the adjusted goodness of fit index (AGFI) and the non-normed fit index (NNFI) should exceed 0.80. All the parameters shown in Table 2 and Table 3 were AMOS estimates obtained using maximum likelihood estimation.

In this study, measurement model comprised Model 1 (M1) and Model 2 (M2). M1 was a full model which comprised first-order latent variables (ITMM, ITAIL, MI, PI, RI, BI), second-order latent variable (ITAL), and the observation variables of these latent variables. M2 was a measurement model of second-order latent variable (ITAL), which comprised firstorder latent variables (MI, PI, RI, BI) and their observation variables.

The CFA results were shown in Table 2. For M1, the $\left(\chi^{2 / d f)}\right.$ was 2.803, NNFI was 0.916, GFI was 0.902, CFI was 0.931 and RMSEA was 0.092, suggesting adequate model fit. For M2, the $(\chi 2 / d f)$ was 2.293, NNFI was 0.965, GFI was 0.936, CFI was 0.976 and RMSEA was 0.078 , also suggesting adequate model fit. Additionally, all first-order factor loadings were significant $(p<0.001)$, indicating convergent validity. Generally, these statistics indicated good fit for the measurement model [28]. 
Table 2. Fit index of measurement models

\begin{tabular}{c|c|c|c|c|c}
\hline Models & $\chi \boldsymbol{2} / \boldsymbol{d} \boldsymbol{f}$ & $\boldsymbol{R M S E A}$ & $\boldsymbol{N N F I}$ & $\boldsymbol{C F I}$ & $\boldsymbol{G F I}$ \\
\hline M1 & 2.803 & 0.092 & 0.916 & 0.931 & 0.902 \\
M2 & 2.293 & 0.078 & 0.965 & 0.976 & 0.936 \\
M3 & 2.95 & 0.076 & 0.91 & 0.92 & 0.90 \\
\hline
\end{tabular}

Path coefficient and estimate of correlation of measurement model were shown in Table 3. All factor loadings were significant $(p<0.001)$, suggesting all parameters were effective statistics. SFL of items were all beyond 0.67 , suggesting these factors could explain more than $40 \%$ information of their latent variables. AVE of items were all beyond 0.5 , suggesting this model's convergent validity was good. Values of items' composite reliability (CR) were all beyond 0.70, suggesting this model's composite reliability (CR) was also good. As same as M1, all the results of M2 were beyond threshold, suggesting M2's convergent validity and reliability was also good. Thus, the four first-order factors could express their second-order factor (ITAL). Results of discriminant validity test showed that the correlation coefficient of M1 and M2 were from 0.60 to 0.82 , which suggesting the discriminant validity was good. On the whole, the measurement models can fit observed data well.

\subsection{Path analysis}

Path analysis was used to examine the significance and strength of the hypothesized effects in the research model. According to the analysis of measurement model, it was suitable for the further analysis of structural model. The structural model (M3, see Figure 2) was used to further validate the impact paths of all the variables, in order to verify the rationality of hypothesis. Figure 2 showed the path coefficients and path significance.



Figure 2. Results of structural model (M3)

The CFA results of M3 were shown in Table 2: $\chi 2 / \mathrm{df}$ had a value of 2.95, RMSEA was 0.076, which was less than 0.8; and NNFI (0.91), CFI (0.92), GFI (0.90) all exceeded 0.90. All the parameter estimations exceeded the threshold. Hence, it was proved that the structural model (M3) fitted the data well. Accordingly, the results indicated that $\mathrm{H} 1$ and $\mathrm{H} 3$ were supported, but $\mathrm{H} 2$ was not supported. This means IT management mechanism had a significant, positive and direct impact on IT application level, but no significant direct impact 
on IT application innovation level. IT application level, while, had a significant, positive and direct impact on IT application innovation level.

Table 3. Standardized parameter estimates and t-value for confirmatory factor analysis $(n=216)$

\begin{tabular}{|c|c|c|c|c|c|c|}
\hline $\begin{array}{c}\text { Latent } \\
\text { Variables }\end{array}$ & $\begin{array}{c}\text { Measurement } \\
\text { Variables }\end{array}$ & $\begin{array}{c}\text { Cronbach's } \alpha \\
\text { (Standardized) }\end{array}$ & $\begin{array}{c}S F L^{a} \\
(T-v a l u e)\end{array}$ & $R 2$ & $C R$ & $\boldsymbol{A} \boldsymbol{V E}$ \\
\hline MI & $\begin{array}{l}\mathrm{MI}_{1} \\
\mathrm{MI}_{2}\end{array}$ & 0.835 & $\begin{array}{l}0.80 * * *(-) \\
0.90 * * *(14.847)\end{array}$ & $\begin{array}{l}0.64 \\
0.81\end{array}$ & 0.84 & 0.73 \\
\hline PI & $\begin{array}{l}\mathrm{PI}_{1} \\
\mathrm{PI}_{2} \\
\mathrm{PI}_{3}\end{array}$ & 0.885 & $\begin{array}{l}0.78^{* * *}(-) \\
0.82 * * *(12.660) \\
0.86^{* * *}(13.401)\end{array}$ & $\begin{array}{l}0.60 \\
0.66 \\
0.74\end{array}$ & 0.86 & 0.67 \\
\hline RI & $\begin{array}{l}\mathrm{RI}_{1} \\
\mathrm{RI}_{2} \\
\mathrm{RI}_{3} \\
\mathrm{RI}_{4}\end{array}$ & 0.943 & $\begin{array}{l}0.67 * * *(-) \\
0.97 * * *(12.721) \\
0.97 * * *(12.716) \\
0.83 * * *(11.215)\end{array}$ & $\begin{array}{l}0.45 \\
0.93 \\
0.95 \\
0.96\end{array}$ & 0.92 & 0.86 \\
\hline BI & $\begin{array}{l}\mathrm{BI}_{1} \\
\mathrm{BI}_{2}\end{array}$ & 0.789 & $\begin{array}{l}0.79 * * *(-) \\
0.72 * * *(10.201)\end{array}$ & $\begin{array}{l}0.62 \\
0.51\end{array}$ & 0.73 & 0.57 \\
\hline ITMM & $\begin{array}{l}\text { ITMM }_{1} \\
\text { ITMM }_{2} \\
\text { ITMM }_{3} \\
\text { ITMM }_{4} \\
\text { ITMM }_{5} \\
\text { ITMM }_{6} \\
\text { ITMM }_{7}\end{array}$ & 0.954 & $\begin{array}{l}0.91 * * *(-) \\
0.89 * * *(18.949) \\
0.92 * * *(18.071) \\
0.83 * * *(19.206) \\
0.80 * * *(15.812) \\
0.86 * * *(14.914) \\
0.83 * * * \text { ( } 19.898)\end{array}$ & $\begin{array}{l}0.91 \\
0.89 \\
0.92 \\
0.83 \\
0.80 \\
0.86 \\
0.83\end{array}$ & 0.95 & 0.75 \\
\hline ITAIL & $\begin{array}{l}\text { ITAIL }_{1} \\
\text { ITAIL }_{2} \\
\text { ITAIL }_{3}\end{array}$ & 0.834 & $\begin{array}{l}0.80 * * *(-) \\
0.78 * * *(11.981) \\
0.79 * * *(12.314)\end{array}$ & $\begin{array}{l}0.80 \\
0.78 \\
0.79\end{array}$ & 0.83 & 0.62 \\
\hline $\begin{array}{c}\text { Second-order } \\
\text { Latent Variables } \\
\text { ITAL }\end{array}$ & $\begin{array}{c}\text { First-order } \\
\text { Latent Variables } \\
\text { MI } \\
\text { PI } \\
\text { RI } \\
\text { BI }\end{array}$ & 0.941 & $\begin{array}{l}0.94 * * *(-) \\
0.82 * * *(10.080) \\
0.81 * * *(9.057) \\
0.92 * * *(10.819)\end{array}$ & $\begin{array}{l}0.89 \\
0.68 \\
0.66 \\
0.85\end{array}$ & 0.93 & 0.76 \\
\hline
\end{tabular}

${ }^{a}$ indicates a parameter fixed at 1.0 in the original solution. SFL is the standardized factor loadings. $t$-value for item factor loadings are indicated in parentheses. CR-Composite reliability, AVE-Average variance extracted.

To analyze mediating effect, we tested two sub-models (shown in Figure 3 ) and the third model that was the same as model M3 (shown in Figure 2). The parameter estimations of the three models suggested that IT application level had a full mediating effect between IT management mechanism and IT application innovation level, which explained the reason why H2 was unsupported. Meanwhile, H4 was supported (see Table 4). 


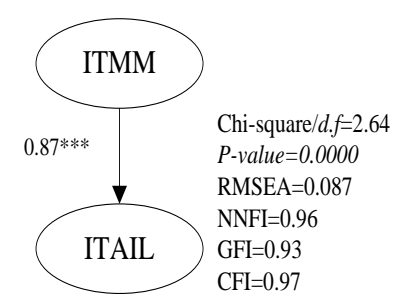

(1)



(2)

Figure 3. Results of mediating effect analysis

Table 4. Path analysis and hypothesis testing results

\begin{tabular}{c|c|c}
\hline Path & Standard Factor Load & Conclusions \\
\hline H1:ITMM $\rightarrow$ ITAL & $0.97^{* * *}$ & suported \\
H2:ITMM $\rightarrow$ ITAIL & 0.08 & unsuported \\
H3:ITAL $\rightarrow$ ITAIL & $0.81^{*}$ & suported \\
H4:ITMM $\rightarrow$ ITAL $\rightarrow$ ITAIL & $0.97^{* *} \times 0.81^{*}$ & suported \\
\hline
\end{tabular}

\section{Conclusions}

From different perspectives, there are many ways to improve the performance of IT application innovation level. This investigation, from management view, provided an empirical evidence for managers to improve IT application innovation level using data collection of manufacturing enterprises of Jiangsu province, China. The main findings were discussed and proposals for action were presented as follows.

Firstly, IT management mechanism of manufacturing firm has significant, positive and direct effects on the IT application level. This indicates that IT application level can be improved from the enhancement of efficiency of organization management, capital investment, and leader's willingness. In practices, the levels of the former two types of indexes are visible and easy to be measured. However, the willingness that presents as states of mind, such as learning, training, and communication, is hard to be measured. Therefore, it might be not effective to achieve the desired aims just depending on simple inputs of resources, and should be complemented by investment in "soft elements". The managers also need change their willingness of IT applications. They should change their attitudes from opposing or indifferent into endogenous support. Through above-mentioned approaches, IT application level might be enhanced quickly and effectively.

Secondly, IT management mechanism of manufacturing enterprise doesn't have significant direct effects on the IT application innovation level. This is quite different from our assumption. It indicates that the improvement in organization management may not be an effective way to enhance the IT application innovation level. However, results of mediating effect test show that IT management mechanism has a significant and indirect impact on IT application innovation level through enhancing IT application level. So, improvement of IT management mechanism can eventually promote IT application innovation level. The path is promoting IT application level firstly and then enhancing the IT application innovation level secondly.

Thirdly, IT application level of manufacturing enterprise has significant, positive and direct effects on the IT application innovation level. It is consistent with the judgment in the theory of technology innovation, which argues that IT extension, and application can also be understood as a stage in the process of IT innovation itself. When some ideas, methods, or 
technologies are not suitable for IT applications in the organizations, the enterprises have to make some adjustment. This process is bound to promote the generation of IT innovation. Thus, IT application level is a decisive factor of IT application innovation level. So, in order to improve IT application innovation level, great efforts should be made to promote IT application level in several key functional areas, such as management, production, research \& development, and business.

In conclusion, the empirical research confirms once again that the process of promoting IT application innovation level in manufacturing enterprises is complex and tortuous. Otherwise, the research objects are selected based on a representative region - Yangtze River Delta Economic Zone, Jiangsu. It includes a variety of industries, and different levels of manufacturing enterprises. Therefore, the study results can be generalized to all manufacturing firms, and provide practical and scientific guidance to promote their IT application innovation process.

\section{Acknowledgements}

We thank the Education Bureau of Jiangsu (EBJ) (grant no.: 2010SJB630039), Social Science Foundation of Jiangsu (grant no.: 12TQB008), Program for New Century Excellent Talents in University (NCET) and Research Project of Nanjing College for Population Program Management (grant no.: 2010C22) for their financial aid.

\section{References}

[1] X. Wang, J. Jing and Y. Yang, "Research on the Basic Theory and Empirical of the Integration between Informationization and Industrialization", Inform. Sciences of China, vol. 27, no. 11, (2009), pp. 1649-1655.

[2] H. Li, Y. Tian and L. Wang, "Empirical Research about on the Direction of Integration and the Mode of Integration between Informationization and Industrialization", Information Sciences of China, vol. 29, no. 7, (2011), pp. 1021-1026.

[3] L. S. Thakur and V. K. Jain, "Advanced Manufacturing Techniques and Information Technology Adoption in India: A Current Perspective and Some Comparisons", The International Journal of Advanced Manufacturing Technology, vol. 36, no. 5-6, (2008), pp. 618-631.

[4] N. Melville, K. Kraemer and V. Gurbaxani, "Review: Inform. Technology and Organizational Performance: An Integrative Model of IT Business Value”, MIS Quarterly, vol. 28, no. 2, (2004), pp. 283-322.

[5] L. Li and Y. Zhou, "An Evaluation Study on 'New Pattern' of Regional Manufacturing Industry", Management World, no. 6, (2005), pp. 76-83.

[6] V. Wong, V. Shaw and P. J. H. Sher, "Effective organization and management of technology assimilation: the case of Taiwanese information technology firms", Indus. Marketing Mgt., vol. 27, no. 3, (1998), pp. 213-227.

[7] H. Lin and J. Su, "The Evolution of the Industrial Persistent and Dynamic Innovation Model and the Empirical Analysis -- Based on Knowledge Generation Perspective", Science of Science and Management of S\&T, no. 2, (2010), pp. 28-34.

[8] W. Shi and Y. Gao, "The Development Strategy of the Internet of Things: Perspective from Industry Technology Chain", Science \& Technology Progress and Policy, vol. 29, no. 4, (2012), pp. 52-56.

[9] E. Bayraktara, M. Demirbagb and K. S. C. Lenny, "A causal analysis of the impact of information systems and supply chain management practices on operational performance: evidence from manufacturing SMEs in Turkey", Production Economics, vol. 122, no. 1, (2009), pp. 133-149.

[10] S. S. Durmusoglu and B. Gloria, "The use of information technology tools in new product development phases: analysis of effects on new product innovativeness, quality, and market performance", Industrial Marketing Management, vol. 40, no. 2, (2011), pp. 321-330.

[11] E. M. Rogers, "Diffusion of innovations", New York, U.S.A.: The Free Press, (1995).

[12] J. Xu, "Study on Factors and Strategies Affecting the Combinational Development of Information and Industralization", Ph. D Thesis: Huazhong University of Science and Technology, (2008).

[13] P. Theodorou and G. Florou, "Manufacturing strategies and financial performance-the effect of advanced information technology: CAD/CAM systems”, Omega, vol. 36, no. 1, (2008), pp. 107-121.

[14] A. Ordanini and G. Rubera, "How does the application of an IT service innovation affect firm performance? A theoretical framework and empirical analysis on e-commerce", Information \& Management, vol. 47, no. 1, (2010), pp. 60-67. 
[15] R. Evangelista and A. Vezzani, "The economic impact of technological and organizational innovations: a firm-level analysis", Research Policy, vol. 39, no. 10, (2010), pp. 1253-1263.

[16] C. Yu, X. Bi, B. Yu and X. Qi, "Research on the Dynamic Mechanism of Information Technology Absorptive Capability Evolution", Journal of Information Science of China, vol. 27, no. 12, (2009), pp. 1880-1884.

[17] A. Jeyaraj, J. W. Rottman and M. C. Lacity, "A review of the predictors, linkages, and biases in IT innovation adoption research", Journal of Information Technology, vol. 21, no. 1, (2006), pp. 1-23.

[18] L. Wu and C. S. Ong, "Management of information technology investment: A framework based on a real options and mean-variance theory perspective", Technovation, vol. 28, no. 3, (2008), pp. 122-134.

[19] H. F. Lin, "An investigation into the effects of IS quality and top management support on ERP system usage", Total Quality Management\& Business Excellence, vol. 21, no. 3, (2010), pp. 335-349.

[20] P. Koellinger, "The relationship between technology innovation, and firm performance: empirical evidence from e-business in Europe", Research Policy, vol. 37, no. 8, (2008), pp. 1317-1328.

[21] J. Hong, P. Huang and Y. Jiao, "Research on Correspondence Degree of Enterprise Informatization", Journal of Information Science of China, vol. 29, no. 1, (2011), pp. 36-41.

[22] R. Fu and K. Bi, “The Development Strategy of China's Manufacture Informatization”, Science and Techno logyM anagem ent Research, no. 9, (2009), pp. 378-379.

[23] J. He, "The Path to Innovative Enterprises: An Analysis Based on Technological Capability and Innovation Strategy", Journal of Soft-Science of China, no. 4, (2012), pp. 143-152.

[24] A. Fosfuri and J. A. Tribø, "Exploring the Antecedents of Potential Absorptive Capacity and Its Impact on Innovation Performance”, The Int'l Journal of Management Science, vol. 36, no. 4, (2008), pp. 173-187.

[25] P. Zeng, T. Deng and X. Zeng, "IT infrastructure, knowledge sharing and organizational innovation -empirical evidence come from enterprises in Pearl River delta", Studies in Science of Science, vol. 29, no. 11, (2011), pp. 1696-1706.

[26] P. Wang and N. C. Ramiller, "Community learning in information technology innovation", MIS Quarterly, vol. 4, no. 33, (2009), pp. 709-734.

[27] X. Wan, Q. Shi and J. Liu, "Comparison of Manufacturing Innovation Network among Shanghai, Jiangsu and Zhejiang -- A Research Based on Input - output and Network Analysis”, Science of Science and Management of S. \& T., vol. 32, no. 2, (2011), pp. 64-72.

[28] Z. Wen, L. Chang, K. Hau and H. Liu, "Testing and Application of the Mediating Effects", Acta Psychologica Sinica, vol. 36, no. 5, (2004), pp. 614-620.

\section{Authors}

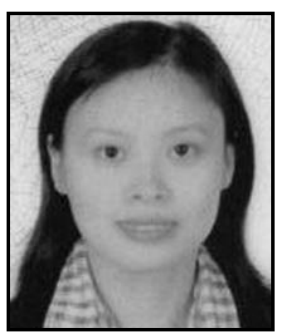

\section{Wenwen Pan}

She received her M.A. (2006) in the School of Economic and Management at Southeast University of China. She is currently a PhD. candidate in MIS at Nanjing University, and a lecturer of College of Economics and Management at Nanjing University of Posts and Telecommunications. Her research has focused on Egovernment and MIS. She has published in the International review of administrative sciences (IRAS), The Electronic Library (TEL), etc...



\section{Guangwei Hu}

He received his Ph. D. (2006) in the School of Economic and Management at Southeast University of China. Now, he is an Associate Professor of MIS in the School of Information Management at Nanjing University, China. His current research has focused on issues of MIS, EGov and Strategic Management. He has published in the Journal of American Society for Information Science and Technology (JASIST), Government Information Quarterly (GIQ), International Review of Administrative Sciences (IRAS), etc... 